was directed to the most pressing needs of the moment. It was pointed out that in some regions, such as India, Malaya, and South Africa, great progress had been made in the systematic study of their floras, but that in others, such as East Africa and some of the West Indian islands, little had yet been done to explore the vegetation resources. In urging that further facilities should be afforded to British botanists to go out and explore the floras of our overseas dependencies, Dr. Hill stated that at present we were indebted chiefly to foreign botanists for a knowledge of the plants of some parts of the Empire. A strong appeal was made for temporary interchanges of posts between overseas and home botanists. The value of a detailed botanical survey was emphasised, especially from the point of view of the economic resources and possibilities of the Dominions, Colonies, and Protectorates.

Another important and closely allied subject dealt with at the conference was the consideration of the best means of promoting the study of natural vegetation of the Empire in its ecological aspect. This was introduced by Mr. A. G. Tansley. It was pointed out that the modern study of vegetation regards each kind of plant covering, be it forest, scrub, or grassland, as having a natural life, economy, and history of its own. If a given type of vegetation is sufficiently well adapted to the local climate and soil, not threatened by the invasion of plants better adapted to all the conditions, and undisturbed by man, it will maintain itself indefinitely. Many kinds of vegetation are, however, mere transition phases to other types, which gradually replace the former covering by the natural invasion of individuals of different species, as, for example, when new soil, such as the alluvium of a river, blown sand, or the like, is occupied first perhaps by grasses, then by shrubs, and finally by trees. Again when forest is felled or burned, or when grassland is burned or overgrazed, new plants, often resulting in a different type of vegetation, invade and settle in the area. The original vegetation may or may not ultimately return. All these phenomena of the development of vegetation are referred to as " succession."

Such facts have, of course, long been well known to practical foresters and stock-raisers, but their systematic investigation is a modern study, vigorously pushed forward, especially in the United States, and also in some of our own colonies and Dominions, especially in New Zealand and South Africa, and to some extent in India and Burma. The results have proved most valuable as a practical guide to the treatment of the land. Overgrazing, for example, may greatly lessen or even destroy the value of a cattle range, by crippling the vegetative powers of the dominant pasture plants, and thus letting in less valuable or worthless herbs, "throwing back the succession" to an earlier stage. The range then has to be allowed time to recover by the natural succession of the grasses and other pasture plants which originally occupied it. A carefully regulated system of grazing or burning will maintain the most useful phase of the succession. The first step towards the discovery of the most scientific and therefore the most economical and productive treatment is the careful and thorough study, by trained investigators, of the natural composition, behaviour, and succession of the vegetation. This has been amply proved, to mention but two examples out of many, by the work of Sampson in the United States and of A. H. Cockayne in New Zealand. The laws of behaviour of forests, on which alone can be based the most scientific treatment, are subject to quite similar laws, and a marked feature of this part of the Conference was the hearty support given by men with long practical experience of forestry work, such as Prof. Troup, of Oxford, who was for many years a member of the Indian Forest Service, and by Mr. R. S. Hole, for some years botanist at the Forest Research Institute at Dehra Dun, to the proposals of the conference.

After very brief summaries of the present state of knowledge of the vegetation of the Crown Colonies and Protectorates, and of the Dominions, and a series of papers from representative men of experience of such work in different parts of the Empire, there was a general discussion, concluding with resolutions. These aimed at the creation of a small central body to superintend the preparation of a series of outline monographs on the vegetation of the different parts of the Empire. Though our knowledge is still, of course, very incomplete, it is of great importance to collect and present what we do know in accessible form, which will serve as a starting-point for further work. It is further proposed to arrange for the systematic record of future work uniform with the monographs. It is also proposed that the central body, when formed, should at once put in hand the preparation of a pamphlet or small handbook, co-operatively produced by the best available authorities in the Empire, dealing with the aims and best methods of field work in the study of different kinds of vegetation, so that a practical guide may be available for new workers in this field throughout the Empire. The conference also adopted a resolution that an adequate training for work on vegetation should involve a practical training in systematic botany and ecology by competent teachers in the field.

At the closing session of the conference Prof. F. O. Bower gave a striking address on the training of botanists, the possibility of effecting interchanges of staffs, and the need for further facilities for research, which was followed by an animated discussion.

The conference terminated with a hearty vote of thanks to Sir David Prain for presiding over its labours. F. T. BRooks.

\title{
The Maximum Recorded Temperature of the Air and its Circumstances.
}

$\mathrm{I}$ the midst of the semi-desert plain of Jefara, between the coast of Tripolitania and the interior plateau, there exists an official Italian settlement situated about 25 miles south of Tripoli and 25 north of Gharian at some 300 feet above sea-level, known as Azizia. In I9I3 Prof. Filippo Eredia, as a member of an agricultural commission, visited the locality, and wisely saw to the establishment of a meteorological station on the lines followed at many other points in the colony. He took great pains to ensure the accurate functioning of the instruments after approved methods, and has recently published the results for a period of seven, not, however, consecutive years :
I913, I9I4, I9I5, I9I9, I920, I921, I922. (Ministero delle Colonie. Sul Clima di Azizia (Tripolitania), Rome 1923.)

The mean yearly temperature for this period is $70 \cdot 8^{\circ} \mathrm{F} .\left(2 \mathrm{I} \cdot 6^{\circ} \mathrm{C}\right.$.), not an excessively high figure, but appropriate to the latitude well outside the northern tropic, the range being between $87.4^{\circ} \mathrm{F}$. $\left(30 \cdot 8^{\circ} \mathrm{C}\right.$.) in July and $52 \cdot 8^{\circ} \mathrm{F}$. (II.6. C.) in January. Therefore, though the summer is torrid, there is a very decided cool season, slight frost being occasionally experienced with an absolute minimum for the period in question of $3 I \cdot I^{\circ}$ F. $\left(-0.5^{\circ}\right.$ C. $)$ in December. Maximum temperatures as high as $1 \mathrm{IO}^{\circ} \mathrm{F}$. $\left(43^{\circ} 3^{\circ} \mathrm{C}.\right)$, the figure

No. 2860 , vol. I I 4 ] 
for each of the five months May to September, the absolute maximum occurring with cloudless sky and S.W. wind, on September I3, I922, namely $136.4^{\circ} \mathrm{F}$. $\left(58.0^{\circ} \mathrm{C}\right.$.), during a period of extremely high temperature throughout Tripolitania, even the coastal city of Tripoli recording as high as $\operatorname{II} 3^{\circ} \mathrm{F}$. $\left(45^{\circ} 0^{\circ} \mathrm{C}\right.$.). This appears, and is so represented by Eredia, to be the highest authentic temperature of the air ever recorded on the globe, exceeding by $2.3^{\circ} \mathrm{F}$. $\left(\mathrm{I} \cdot 3^{\circ} \mathrm{C}\right.$.) the previous "record" of $\mathrm{I} 34^{\circ} \cdot \mathrm{I}^{\circ} \mathrm{F} .\left(56 \cdot 7^{\circ} \mathrm{C}\right.$. $)$ in Death Valley, in the south-eastern desert of California, on July xo, I9I3, occurring, that is, in a similar, or rather higher latitude, close to the summer solstice, when the sun is nearly vertical. Records exceeding II $5^{\circ} \mathrm{F}$. $\left(46^{\circ} \mathrm{C}\right.$.) are stated to be common in Tripolitania, whilst other extremes from other regions, quoted for comparison, are $127.4 \mathrm{~F} .\left(53.0^{\circ} \mathrm{C}\right.$. $)$ in the Wargla oasis of Algeria, on July $\mathrm{I} 7, \mathrm{x} 879$, and $\mathrm{I} 25^{\circ} 9 \mathrm{~F}$. $\left(52 \cdot 2^{\circ}\right.$ C. $)$ at Jakobabad in N.W. India, on June I 3 , 1897.

The remarkable circumstance connected with the Azizia " record " is, we think, not so much the extratropical location, since it is towards the dry. subtropical belts, where the days are longer, that the most intense summer heats occur, but that the season of its occurrence there should have been equinoctial. The mean temperature of the month of September for the seven years in question is exceedingly high, surpassing not only that of May, which is usual in northern extra-tropical latitudes, but also that of June, which is quite abnormal. This anomaly appears to be a local accentuation of the common Mediterranean characteristic of excessive summer heat lingering to a later date than in higher latitudes, where the much greater difference in the length of the day between solstice and equinox usually permits a rapid decline in temperature when August is over. Yet we know that even in England there comes every few years, with a drift northward of warm Mediterranean air, a surprising development, or resumption, of severe heat in September, with afternoon maxima at about $90^{\circ} \mathrm{F} .\left(32^{\circ} \mathrm{C}\right.$.), which sometimes causes the climatological student to wonder how the oblique equinoctial sunshine in this latitude has enough strength to raise the temperature to such levels. It should be remembered, however, that apart from the large reserve of heat stored in the air and the land- and seasurface in autumn, and its easy transport by air currents from heated southern regions, enabling a smaller amount of solar radiation to raise the temperatiure to $80^{\circ}$ or $90^{\circ} \mathrm{F}$. $\left(27^{\circ}\right.$ to $32^{\circ} \mathrm{C}$.) than is necessary early in the summer, the very fact that the equinoctial sunshine is feebler, implying a smaller amount of surface heating, involves in turn, in conjunction with the relatively warm upper air in the autumn, a shallower vertical temperature gradient, and lessened tendency to convection, than at the high solstice. The result of this is that the heat is kept more to the surface, and that September " heat-waves," when they do occur, are liable to be scarcely less severe than those of July and August, and rather more so than those of May and June, when the fierce insolation, coupled with the yet cold upper air in early summer, favours instability with removal of the warm air from the surface and a checking of the afternoon maxima.

The circumstances attending the highest temperature which has yet been "caught" by our observing stations, may be summarised as follows: It occurred during a period of cloudless sky with light winds from the heated regions of the Sahara, in the middle of a semi-desert plain well inland from the sea, in a latitude $\left(32 \frac{1}{2}^{\circ} \mathrm{N}\right.$.) which, astronomically at least, belongs to the temperate zone, at a date (Sept. I3) only ten days on the summer side of the autumn equinox, when the sun is nearly half-way between its extreme solstitial position. The time of year is a prominent illustration of the general climatological principle that the seasonal extremes of temperature, even in continental regions, tend to lag well behind the corresponding extremes in the intensity and duration of sunlight. The latitude, too, illustrates the somewhat paradoxical principle that in general it is not the equatorial or hottest climates, that is, those with the highest mean temperatures, that furnish the occasional extremes of heat, say above $120^{\circ} \mathrm{F}$. (circ. $50^{\circ} \mathrm{C}$.), but the cooler and drier climates, near the confines of the tropics, which are intensely hot during the summer months.

L. C. W. Bonacina.

\section{Past and Passing Peoples of Polynesia.}

SOME important studies of two Polynesian peoples are published by the Bayard Dominick Expedition in the Memoirs of the Bishop Museum at Honolulu. ${ }^{1}$ In vol. ix. Mr. H. D. Skinner gives a comprehensive account of the almost extinct Morioris of Chatham Islands. Of these only two living representatives were found in a population of foreigners, most of whom were Maoris. One other was living in New Zealand. In vol. viii. Mr. R. Linton discusses the material culture of the Marquesans, and in vol. ix. Mr. L. D. Sullivan their somatology. These are also a dying and diseased race and Mr. Sullivan doubts whether there is a wholly sound physical specimen alive, while Mr. Linton considers that their language and portions of their culture may be preserved for several generations by their numerous half-Chinese or half-European descendants, who are more resistant to disease than the pure-blooded natives.

Mr. Linton's account of the Marquesans is restricted

1 "'The Material Culture of the Marquesas Islands." By Ralph Linton Memoirs of the Bernice P. Bishop Museum, vol. viii. No. 5 (Bayard Dominick Expedition. Publication No, 5.) Honolulu, Hawaii, r923.

"The Morioris of Chatham Islands." By H. D. Skinner. Memoirs of the Bernice P. Bishop Museum, vol. ix. No. r. (Bayard Dominick Expedition. Publication No. 4.) Honolulu, Hawaii, 1923

"Marquesan Somatology with Comparative Notes on Samoa and Tonga.' By Louis R. Sullivan. Memoirs of the Bernice P. Bishop Museum, vol. ix No. 2. (Bayard Dominick Expedition. Publication No. 6.) Honolulu, Hawaii, I923.

$$
\text { NO. } 2860 \text {, VOL. I I } 4]
$$

to their material culture, and other features having been dealt with elsewhere, only a short summary is given of social organisation and religion. But houses, canoes, stone artifacts, weapons and implements, clothing and ornament are described in detail and illustrated by forty-four full-page plates and eleven figures in the text. The few local differences in the islands are set out in a comparative table, which is repeated in greater detail to exhibit the relations of the Marquesan material culture to that of other Polynesian groups. Samoa and Tonga are found to have a closer cultural agreement than any other two localities. The Marquesas and New Zealand are almost equally close. The Society Island culture comes between the Samoan-Tongan and the MaoriMarquesan. Hawaiian culture resembles the MaoriMarquesan on the material side, but is more nearly related on the non-material side to the Society Islands and Western Polynesia.

The author gives the following hypothesis of the historic distribution of races and culture in the Pacific. The first arrivals in Central and South-east Polynesia were Negroid and Melanesian rather than Polynesian in culture. They settled in Tonga, Samoa, the Cook, Society, Austral, and Tuamotu groups. They did not reach the farther islands and came from Melanesia, probably Fiji. The next comers 